\title{
The Effect of Oxytocin Receptor Blockade on Parturition in Guinea Pigs
}

\author{
Jean-Claude Schellenberg
}

Research Center for Reproductive Medicine, Department of Obstetrics and Gynecology, University of Auckland, Auckland, New Zealand

\begin{abstract}
The mechanism of the onset of labor is unknown in humans and guinea pigs. Contrary to most other species, progesterone withdrawal appears not to precede the onset of labor. To elucidate the role of oxytocin in the onset and maintenance of labor, guinea pigs were fitted with vascular catheters, an intraabdominal pressure catheter and an array of uterine electromyogram electrodes. An oxytocin antagonist (des-Gly ${ }^{9}$-[D-Trp ${ }^{2}$, Thr $\left.^{4}, \mathrm{Orn}^{8}\right] \mathrm{dC}^{6}$-oxytocin, $20 \mu \mathrm{g} / \mathrm{kg}$ per $h, n=11)$ or saline solution $(n=12)$ was infused starting on day 66 of gestation (term is $69 \mathrm{~d}$ ). Oxytocin receptor blockade resulted in decreased uterine activity and a prolonged expulsive phase (second stage) of labor. Fetal delivery was delayed and fetal mortality was increased. The onset of the expulsive phase of labor was delayed but maximum uterine activity occurred in time together with a timely change in uterine electromyogram activity from a prepartum to a postpartum pattern following an unaltered progressive increase in baseline uterine activity. This indicates that oxytocin is requisite for the normal progress of the first and second stage of labor, but has no involvement in the mechanism of the onset and the timing of labor. ( $J$. Clin. Invest. 1995. 95:13-19.) Key Words: labor onset • labor stage, first • labor stage, second • prostaglandins $F \cdot$ progesterone
\end{abstract}

\section{Introduction}

Progesterone withdrawal is an obligatory event for the initiation of labor in most species $(1,2)$. Humans, guinea pigs, and most monkeys studied represent an apparent exception to this rule; maternal plasma concentrations of progesterone do not fall before the onset of labor and attempts to demonstrate a prepartum progesterone withdrawal of any sort have so far failed (14). In sheep, the species most extensively studied in regard to parturition, a causal relationship exists between rising concentrations of fetal plasma cortisol, induction of placental $17 \alpha$ hydroxylase, increased production of estrogens and decreased production of progesterone by the placenta, increased estrogen/ progesterone ratio in maternal plasma, uterine PG synthesis, and labor $(3,4)$. In humans, guinea pigs, rhesus monkeys, and baboons, placental $17 \alpha$-hydroxylase is absent and the chain of

Address correspondence to Dr. J.-C. Schellenberg, Department of Obstetrics and Gynaecology, National Women's Hospital, Auckland, New Zealand, Phone: 9-638-9919; FAX: 9-630-9858.

Received for publication 15 July 1994 and in revised form 23 September 1994

J. Clin. Invest.

(c) The American Society for Clinical Investigation, Inc.

0021-9738/95/01/0013/07 \$2.00

Volume 95, January 1995, 13-19 events leading to the onset of labor remains unidentified $(1,2$, $4,5)$.

Oxytocin has long been held to play an essential part in human parturition, but its physiological role remains controversial $(1,2)$. Oxytocin is one of the most potent stimulators of uterine contractions in vitro (6) and in vivo (7). As term approaches, labor can be induced with diminishing doses of oxytocin in all species studied including humans and guinea pigs $(1,8,9)$. Several studies have suggested that oxytocin concentrations in human plasma remain unchanged during the first stage of labor and increase inconsistently during the second stage of labor (expulsive phase) (9-11). A recent study using frequent sampling strongly suggests that oxytocin is secreted in irregular short pulses which are more frequent and of longer duration in early labor than before labor, and increase further in length and frequency during the second and third stage of labor (7). As the observed plasma concentrations were similar to concentrations required to elicit uterine contractions by administration of exogenous oxytocin, a physiological role of the observed oxytocin pulses was proposed (7). In a study on five guinea pigs, oxytocin was undetectable in maternal plasma during the first stage of labor $(<4$ pmol/liter, total of four samples taken from three guinea pigs) but was present in nanomolar concentrations during the second stage in all five guinea pigs (12). In rhesus monkeys, nocturnal surges of oxytocin occurring towards term in maternal plasma are associated with increased uterine activity $(13,14)$.

Oxytocin receptors increase towards term in myometrium in all species studied (15-17). In humans, myometrial oxytocin receptors increase 30 -fold between early pregnancy and early labor when they attain peak concentrations (16). In guinea pigs, myometrial oxytocin receptors increase 50 -fold between days 10 and 60 of gestation, after which their concentration remains unchanged until post partum (18). While an increase of oxytocin receptors at the time of the onset of labor may indicate a role in the initiation of labor, as has been suggested for human parturition (16), it may also merely represent one of the many changes occurring in preparation for later stages of labor and the postpartum period (2). In endometrium, oxytocin receptors have been demonstrated during pregnancy in humans and guinea pigs $(16,19)$. In humans, oxytocin stimulates the production of $\mathrm{PGF}_{2 \alpha}$ by decidua in vitro $(20,21)$. Receptors for oxytocin have also been found in human amnion and chorion but there is conflicting evidence on whether receptors increase in relation to labor $(22,23)$. Oxytocin mRNA in chorio-decidual tissue is present in three to fourfold higher concentrations after vaginal delivery than before the onset of labor, suggesting an autocrine or paracrine role for oxytocin in labor (24).

These observations do not provide conclusive evidence for a physiological role of oxytocin either in the initiation or the maintenance of labor. To obtain this information, experiments with oxytocin antagonists are required. Oxytocin receptor blockade may arrest some cases of human preterm labor (25), and inhibits spontaneous contractions in rhesus monkeys (13, 
14) and oxytocin-induced contractions in baboons (26), but its effect on the onset and maintenance of labor has been studied only in rats, in which no effect was found (27). The relevance of observations made in rats to human labor is dubious as the physiology of parturition differs fundamentally between the two species. In rats, the maintenance of pregnancy is dependent on progesterone production by the corpus luteum, and not the placenta as in humans, guinea pigs, and monkeys, and luteolysis plays a central role in the onset of parturition (1). For these reasons we examined the role of oxytocin in the initiation and maintenance of labor in guinea pigs.

\section{Methods}

Animals and treatments. Permission for this study was obtained from the institutional Animal Ethics Committee. Husbandry and operative procedures have been previously described (28). In brief, male and female guinea pigs of mixed breed were housed together until $24 \mathrm{~h}$ after vaginal opening had occurred (day 2 of gestation). Between 51 and 58 d gestation, a jugular venous catheter, and a carotid arterial catheter were inserted during general anesthesia $(n=23)$. A uterine electromyogram (EMG) ${ }^{1}$ electrode array and an abdominal pressure catheter (28) were inserted in 20 of the 23 guinea pigs ( $n=11$ test animals and $n=9$ controls). The catheters and EMG wires were exteriorized on the guinea pigs' backs and attached to backpacks containing a pressure transducer and connectors. The animals were randomly assigned to receiving either a continuous intravenous infusion $(0.5 \mathrm{ml} / \mathrm{h})$ of the competitive oxytocin antagonist des-Gly ${ }^{9}$-[D-Trp $\left.{ }^{2}, \mathrm{Thr}^{4}, \mathrm{Orn}^{8}\right] \mathrm{dC}^{6}$-oxytocin (F372; Ferring, Malmö, Sweden; $20 \mu \mathrm{g} / \mathrm{kg}$ per h, reference 29) dissolved in heparinized saline ( $1 \mathrm{IU}$ heparin $/ \mathrm{ml} 0.18 \mathrm{M}$ saline solution, $n=11$ ), or of vehicle only $(n=12)$, starting on day 66 at $1,200 \mathrm{~h}$. The infusions were continued until all fetuses were delivered or dead in utero. One guinea pig (No. 94) delivered during a graded infusion of oxytocin while administration of $\mathrm{F} 372$ was continued. Fetal viability in prolonged pregnancies was determined by ultrasound scanning. When death of all undelivered fetuses was confirmed or maternal distress from dystocia was apparent, as indicated by prolonged ineffective pushing (i.e., salvos of intraabdominal pressure rises of $>30 \mathrm{mmHg}$ and $<15 \mathrm{~s}$ duration), uterotomy under halothane/oxygen anesthesia was carried out before death by nitrous oxide. The width of the symphysis pubis was recorded daily (in millimeters) by palpation.

Recording and analysis of uterine activity. On day 65, the guinea pigs were connected to an electronic signal conditioner mounted above the cage, via a swiveling system fitted to the backpacks as described previously (28). The quasi-integrated EMG signal (EMG envelope, reference 28) of the uterus and the abdominal pressure increments were recorded continuously on a computer and a chart recorder connected in parallel. Recording continued until $\sim 24 \mathrm{~h}$ after delivery or termination of the experiment. No correction for signal attenuation was needed as the change in the mean amplitude of the quasi-integrated EMG was $+1 \pm 5 \%$ (SEM) between the first $12 \mathrm{~h}$ after starting treatment and the time from 24 to $36 \mathrm{~h}$ before peak uterine activity (See Fig. 3) occurred. Using software described previously (28), the gain was set to achieve similar amplitudes of the quasi-integrated EMG during the pretreatment period in all animals. The threshold to record an increase above baseline as a contractile event was set at $\sim 5 \%$ of the amplitude of a typical major contractile event preceding labor. Events lasting $<8 \mathrm{~s}$ were filtered out. Uterine activity (area of the quasi-integrated EMG) was expressed as percentage of activity during the $12 \mathrm{~h}$ preceding treatment. For analysis of the effect of oxytocin receptor blockade (Fig. 3), the hourly uterine

1. Abbreviations used in this paper: EMG, electromyogram; F372, desGly ${ }^{9}$-[D-Trp ${ }^{2}, \mathrm{Thr}^{4}, \mathrm{Orn}^{8}{ }^{8} \mathrm{dC}^{6}$-oxytocin; NEMGA, no EMG activity; PGFM, 13,14-dihydro-15-keto-PGF ${ }_{2 \alpha}$, RM-ANOVA, repeated measures ANOVA. activity was calculated, starting from the beginning of the treatment. In F372-treated guinea pigs, records were analyzed only until the F372 infusion was discontinued or an oxytocin infusion was started $(n=2)$.

Analysis of the pattern of contractions. To define the distinctive pattern of uterine contractions occurring before labor, during labor, and after labor, the intervals with no EMG activity (NEMGA) between EMG events were categorized according to their duration (an "event" is defined as the time during which the quasi-integrated EMG signal is above the threshold value; reference 28 ), and the relative frequency of each category of NEMGA intervals was calculated (See Fig. 1). The relative frequency of each category then served as the basis for the analysis of the effect of oxytocin receptor blockade. The relative frequency of NEMGA intervals was determined for each 3-h period starting from the beginning of the treatment (forward analysis) in F372-treated animals or from the time of delivery of the last fetus (forward and backward analysis) in saline-treated animals (See Fig. 3).

Diagnosis of the expulsive phase of labor and delivery. In the 20 guinea pigs carrying an EMG electrode array and an intraabdominal pressure catheter, the onset of the expulsive phase (second stage) of labor and the time of birth of the first and the last fetus were determined from the EMG and the intraabdominal pressure recordings with an error of $< \pm 5 \mathrm{~min}$. The onset of the second stage of labor was defined by the occurrence of pushing, i.e., of salvos of intraabdominal pressure rises of $>30 \mathrm{mmHg}$ and $<15 \mathrm{~s}$ duration during at least $50 \%$ of the contractions. The time of birth was either witnessed or assumed to have occurred at the end of the first episode of regular pushing followed by a pause (first fetus) or the cessation of pushing (last fetus). In the three control guinea pigs not carrying EMG electrodes and balloon catheters, the time of delivery was estimated within an error margin of $\pm 1.5,4$, and $5 \mathrm{~h}$, respectively. For analysis of the time of delivery of the first and the last fetus the same time estimate was used. These three animals were excluded from analysis of the time between the onset of the expulsive phase and delivery, and the time between delivery of the first and the last fetus.

Oxytocin sensitivity tests. In two nonpushing guinea pigs, oxytocin was infused on day 75 , starting at a rate of $0.25 \mathrm{mU} / \mathrm{min}$ and doubling the dose each $45 \mathrm{~min}$ (28), while administration of F372 was continued. One guinea pig was carrying her intact litter of three fetuses (two dead and one alive, No. b94), and the other was carrying one dead fetus, having delivered her third fetus $9 \mathrm{~h}$ before (No. b95).

Blood sampling, hormone determinations. Maternal arterial blood ( 1 or $0.5 \mathrm{ml}$ on alternate days starting on day 66 ) was collected into glass tubes containing $4.5 \mathrm{mg}$ potassium EDTA and $20 \mu \mathrm{g}$ mefenamic acid, centrifuged at $4^{\circ} \mathrm{C}$, and the plasma stored at $-20^{\circ} \mathrm{C}$ until assayed. Estradiol was determined without prior extraction (Estradiol-2 RIA Kit; Sorin Biomedica, Saluccia, Italy; sensitivity $20 \mathrm{pmol} / \mathrm{liter}$, intraassay variability $5 \%$, interassay variability $7 \%$ ). Progesterone was measured following diethyl ether extraction and dilution (Amerlex-M Progesterone RIA Kit; Kodak Clinical Diagnostics, Amersham, UK; sensitivity $0.5 \mathrm{nmol} /$ liter, intraasay variability $5 \%$, interassay variability $7 \%$ ). PGFM was measured by RIA using an antiserum with the following cross-reactivity: 15 -keto-PGF $2 \alpha: 0.9 \% ; 13,14-d i h y d r o-15-k e t o-\mathrm{PGE}_{2}$ : $2 \%$; 15-keto-PGE 2 : $0.3 \%$; 6,15-diketo-13,14-dihydro-PGF ${ }_{1 \alpha}: 4.6 \%$; $\mathrm{PGA}_{2}$ : 0.02\%; all other common PG: $<0.01 \%$ (sensitivity $0.28 \mathrm{nmol} /$ liter, intraassay variability $6 \%$, interassay variability $8 \%$ ).

Statistical analysis. Uterine activity was examined by ANOVA, RM-ANOVA) and $t$ test, hormone concentrations by regression analysis (weighted for the number of points per animal, minimum number of points $n=3$ ) and RM-ANOVA (SAS Institute Inc., Cary, NC); these data were presented as mean \pm SEM. Data subjected to life table analysis (log-rank test) were presented as median or as the $25 \%$ quartile where the median was undefined due to right-censored values (delivery by uterotomy, delivery during oxytocin infusion, or delivery after stopping F372). Differences of $P<0.05$ were considered significant.

\section{Results}

Pattern of uterine activity in control animals. The pattern of uterine contractions in controls occurring before labor differed 


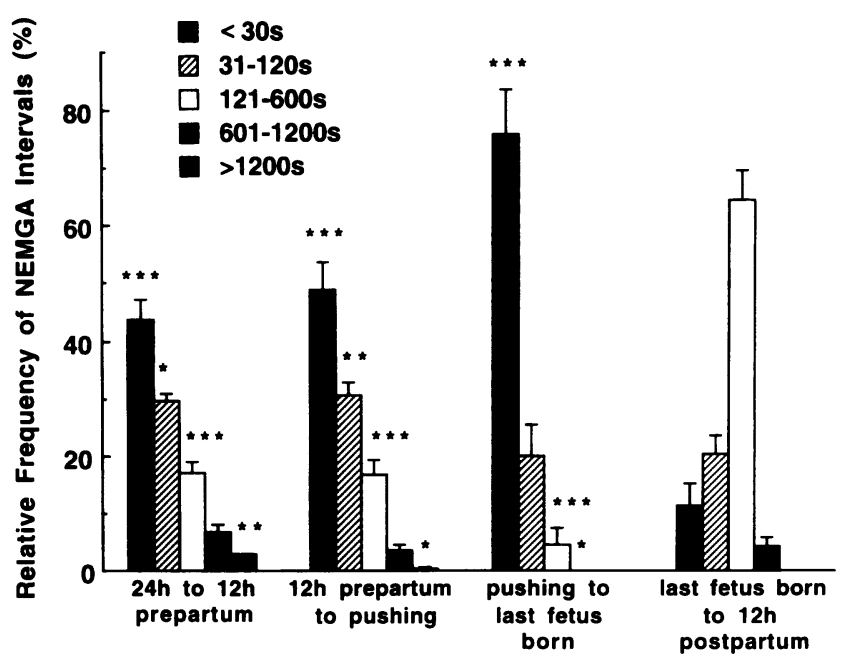

Figure 1. Relative frequency of NEMGA intervals in guinea pigs infused with saline solution. Bars represent ranges of NEMGA intervals $(<30$ s, $31-120 \mathrm{~s}$ etc.). ${ }^{*} P<0.05, * * P<0.01,{ }^{* * *} P<0.001$ by RMANOVA, vs. period from the delivery of the last fetus until $12 \mathrm{~h}$ postpartum. Values are mean \pm SEM.

from that after labor and delivery (Fig. 1). Most striking was the finding in postpartum animals of a significant decrease of the relative frequency of NEMGA intervals of $<30 \mathrm{~s}$ duration compared to the time preceding (and during) labor, and a corresponding increase in NEMGA intervals of 121-600 s duration. These changes occurred in all control animals and appeared to be specific for changes in uterine activity accompanying labor; in one animal they were absent during an episode of increased uterine activity occurring between 38 and $25 \mathrm{~h}$ preceding labor (maximum $350 \%$ above baseline returning to $120 \%$ of baseline).

Uterine activity. Treatment with F372 resulted in a significant transient ( $12 \mathrm{~h})$ decrease of about $20 \%$ in the area of the quasi-integrated EMG (Fig. 2). The amplitude of the quasiintegrated EMG remained unchanged (not shown) suggesting that the frequency of contractions rather than the voltage of the EMG or the frequency of EMG bursts within contractions events (28) was decreased. The time of the onset of labor could not be determined directly as labor was of gradual onset (Fig. 3 ). Therefore, the onset of labor was estimated from the time of occurrence of peak uterine activity (maximum uterine activity per hour). Uterine activity started to rise above baseline approximately $36 \mathrm{~h}$ before peak activity was attained in both F372-treated and in control animals (baseline = mean activity from 45 to $39 \mathrm{~h}$ before peak activity, Fig. 3). The increase of uterine activity above baseline was significant throughout the $27 \mathrm{~h}$ before peak activity ( $P=0.05-0.0001$ by RM-ANOVA) Treatment with F372 did not affect the rise in uterine activity until the $2 \mathrm{~h}$ preceding and the hour during peak activity ( $P$ $=0.03, P=0.002$, and $P<0.001$, respectively). Uterine activity during the hour of peak activity in F372-treated guinea pigs was $375 \pm 52 \%$ of pre-treatment levels (range $164-717 \%$ ) compared to $881 \pm 117 \%$ (range $288-1436 \%$ ) in controls (Fig. 3 ). The number of contractions during expulsion of the first fetus was significantly lower in F372-treated guinea pigs than in controls $(10.2 \pm 2.0$ vs. $21.5 \pm 1.2$ contractions $/ 20 \mathrm{~min}, P=0.0002$ by $t$ test, not shown).

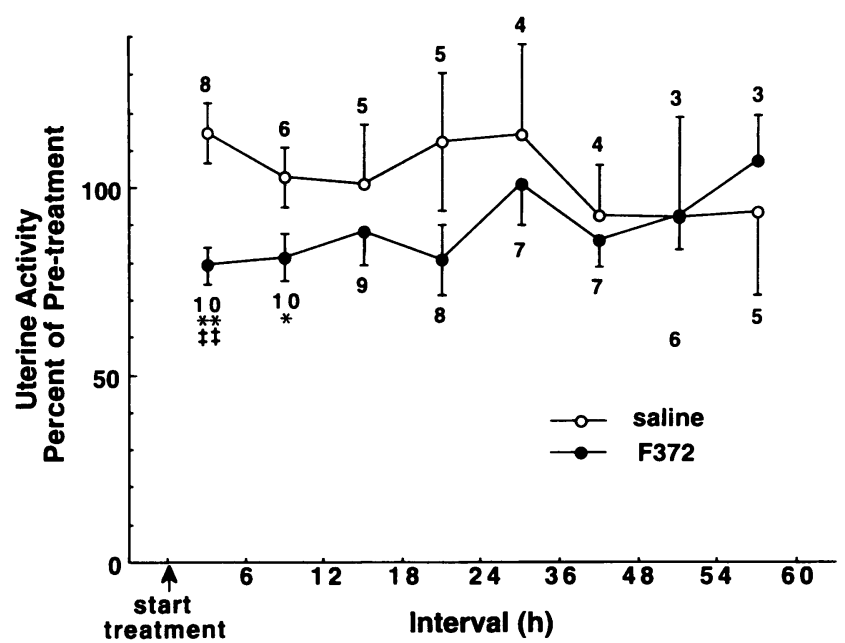

Figure 2. Uterine activity (area of the quasi-integrated EMG signal) for each 6-h interval during the first $60 \mathrm{~h}$ after commencing treatment with the oxytocin receptor blocker F372 or saline solution. EMG activity occurring $<36 \mathrm{~h}$ before peak uterine activity was excluded. $* P<0.05$, $* * P<0.01$, by RM-ANOVA vs. activity during the $12 \mathrm{~h}$ before starting treatment; ${ }^{\ddagger \ddagger} P<0.01$, vs. saline-treated guinea pigs. Values are mean $\pm \operatorname{SEM}(n=3-10)$.

Pattern of contractions. In all F372-treated guinea pigs, as in controls, peak uterine activity was associated with a significant decrease in the relative frequency of NEMGA intervals of $<30 \mathrm{~s}$ duration and an increase in the relative frequency of NEMGA intervals of $121-600 \mathrm{~s}$ duration (Fig. 3). The relative frequency of NEMGA intervals of $<30 \mathrm{~s}$ in F372-treated guinea pigs was similar to controls preceding peak uterine activity, lower during peak activity $(P=0.02)$, and higher during the $12 \mathrm{~h}$ following peak activity (Fig. 3 ). The relative frequency of NEMGA intervals of 121-600 s was similar to controls preceding and during peak uterine activity but less frequent during the following $12 \mathrm{~h}$ (Fig. 3).

Timing of peak uterine activity. Treatment with F372 had no significant effect on the timing of peak uterine activity (median 3.0 vs. $2.8 \mathrm{~d}$ after starting treatment, Fig. 4; mean \pm SEM $3.5 \pm 0.5$ vs. $2.9 \pm 0.5 \mathrm{~d}, P=0.3$ by $t$ test, $n=23$ ). In this analysis the estimated time of delivery of the three control guinea pigs without EMG electrode array was used to represent peak uterine activity. When these three guinea pigs were excluded from analysis, the difference between treatments remained non-significant (median 3.0 vs. $2.3 \mathrm{~d}, P=0.07$; mean \pm SEM $3.5 \pm 0.5$ vs. $2.4 \pm 0.4 \mathrm{~d}, P=0.1$ by $t$ test, $n=20$ ).

Expulsive phase of labor and delivery. Treatment with F372 significantly delayed the onset of the expulsive phase of labor (median 4.0 vs. $2.3 \mathrm{~d}$ after starting treatment, Fig. 5), birth of the first fetus (median 4.0 vs. 2.8 d, Fig. 6) and birth of the last fetus ( $25 \%$ quartile 3.9 vs. 1.9 d, Fig. 7 ). Treatment with F372 prolonged the second stage of labor, increasing the time between the onset of the expulsive phase of labor and birth of the first fetus (median 70 vs. $10 \mathrm{~min}, P=0.003$ ), the onset of the expulsive phase and birth of the last fetus (25\% quartile 119 vs. $24 \mathrm{~min}, P=0.004$ ) and the time between birth of the first and the last fetus ( $25 \%$ quartile 90 vs. $20 \mathrm{~min}, P=0.002$ ).

Fetal outcome. Treatment with F372 was associated with an increased incidence of intrauterine death (diagnosed by maceration) of normally developed fetuses (mean of $0.9 \pm 0.4$ per 


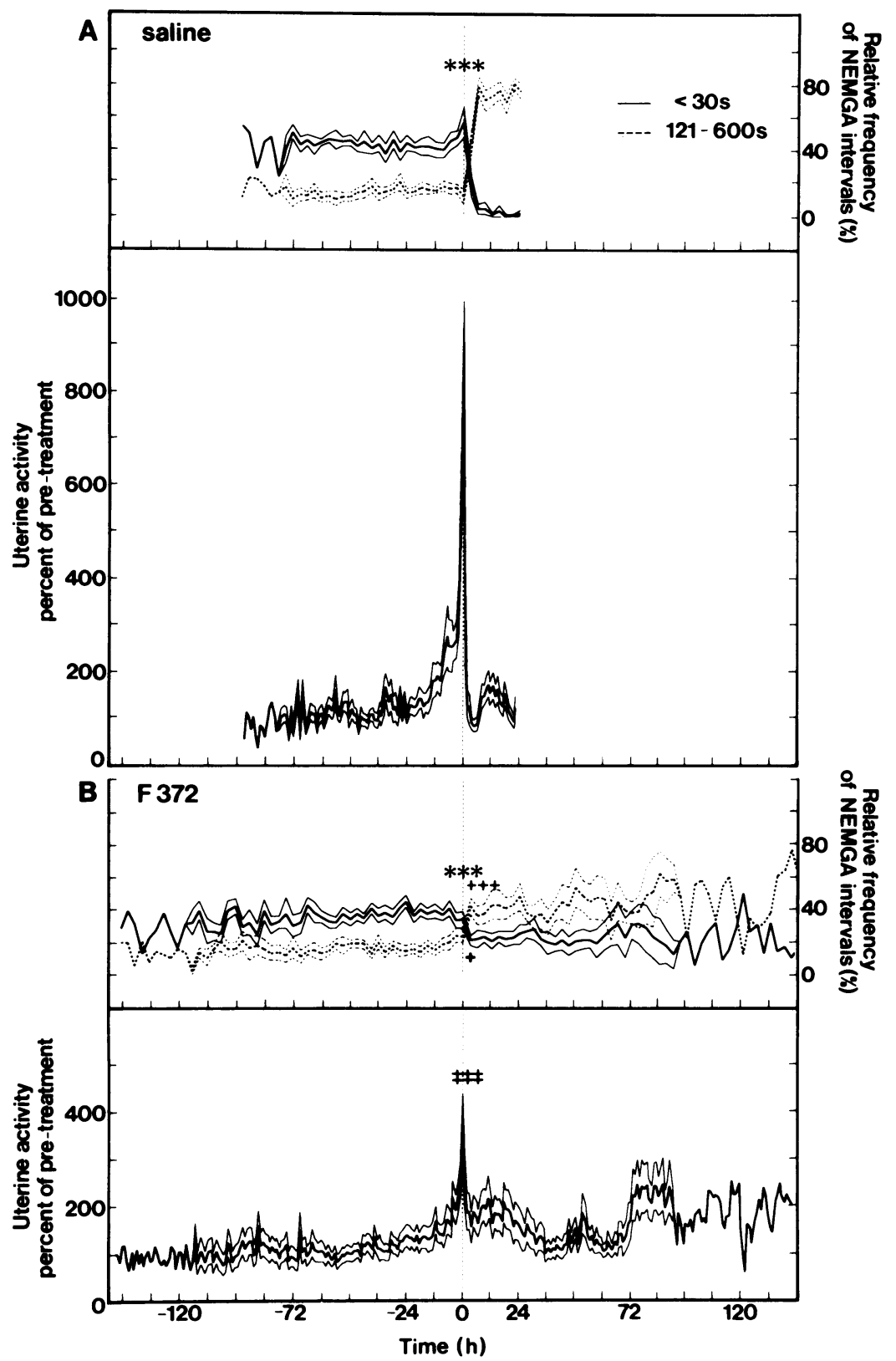

Figure 3. Uterine EMG activity and relative frequency of NEMGA intervals lasting $<30 \mathrm{~s}$ or 121-600 s. Uterine activity is normalized for time 0 (peak uterine activity). (A) Treatment with saline solution $(n=9)$; upper section, relative frequency of NEMGA intervals at time 0 comprises the NEMGA intervals during the $3 \mathrm{~h}$ preceding and including delivery of the last fetus. $(B)$ Treatment with the oxytocin receptor blocker F372 $(n=11)$; upper section, relative frequency of NEMGA intervals at time 0 represents the $3 \mathrm{~h}$ during which peak uterine activity occurred (analysis of NEMGA intervals for each 3-h period was started at the beginning of treatment ). $* * * P<0.0001$ by RM-ANOVA, NEMGA intervals of $<30 \mathrm{~s}$ and of $121-600 \mathrm{~s}$ during the $12 \mathrm{~h}$ preceding and including time $0 \mathrm{vs}$. the $12 \mathrm{~h}$ following time $0 ;{ }^{+} P=0.03$, NEMGA intervals of $<30 \mathrm{~s}$ during the $12 \mathrm{~h}$ following time 0 vs. saline-treated; ${ }^{+++} P=$ 0.001 , NEMGA intervals of $121-600 \mathrm{~s}$ during the 12 h following time 0 vs. saline-treated; ${ }^{\ddagger \ddagger \ddagger} P<0.0001$, vs. peak uterine activity in saline-treated guinea pigs. Values are mean \pm SEM (SEM not shown for $n<3$ ). litter vs. $0, P=0.04$ by $t$ test $)$ and a decreased number of live newborns per litter $(1.3 \pm 0.3$ vs. $2.8 \pm 0.4, P<0.02)$. The number of intrauterine deaths of normally developed fetuses was correlated with the time of birth of the first and the last fetus (both $r=0.7, P<0.001$ ). The mean total number of fetuses per litter $(3.6 \pm 0.4$ vs. $3.8 \pm 0.3)$, total fetal weight per litter $(289 \pm 24$ vs. $322 \pm 27 \mathrm{~g})$, the number of dead runts $(0.7 \pm 0.4$ vs. $0.3 \pm 0.2)$ and the number of nonmacerated dead neonates per litter $(0.7 \pm 0.2$ vs. $0.8 \pm 0.3)$ were not significantly different in animals treated with $\mathrm{F} 372$ and controls.

Softening of the symphysis pubis. Mean symphysial width in F372-treated guinea pigs was not significantly different from controls at the start of treatment $(2.9 \pm 0.4$ vs. $3.0 \pm 0.4 \mathrm{~mm})$ or at the time of peak uterine activity $(5.3 \pm 2.4$ vs. $5.5 \pm 2.5 \mathrm{~mm})$. In three guinea pigs treated with F372, narrowing of the symphysis was observed after peak uterine activity had occurred and then subsided and live fetuses were still in utero.
Oxytocin sensitivity tests. Doubling of baseline uterine activity was achieved with $1 / 2 \mathrm{mU} / \mathrm{min}$ oxytocin in guinea pig No. b94, and with $1 \mathrm{mU} / \mathrm{min}$ in guinea pig No. b95.

Hormone concentrations. No significant changes in the concentrations of PGFM or progesterone occurred preceding and during labor in controls. In F372-treated guinea pigs, concentrations of PGFM were similar to controls until the day when peak uterine activity occurred. On the day after peak activity had occurred, the concentrations started to increase progressively in all F372-treated animals that were undelivered and in whom blood was available for analysis. Progesterone concentrations in F372-treated guinea pigs were similar to those in controls until the day before peak uterine activity, when concentrations started to fall progressively (Fig. 8). An exception was guinea pig No. 94 which delivered one live and two dead fetuses during an oxytocin infusion on day 75; progesterone concentrations decreased by $50 \%$ the day after peak uterine activity occurred 


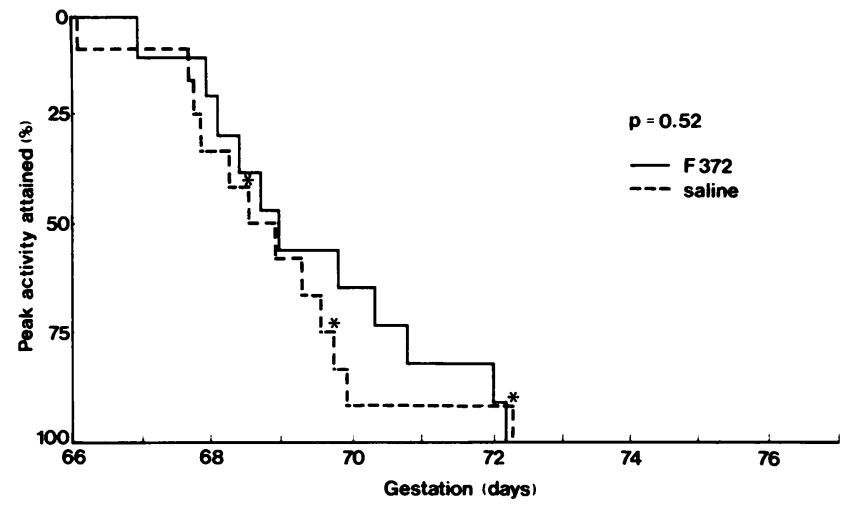

Figure 4. Time of occurrence of peak uterine activity in guinea pigs treated with the oxytocin receptor blocker F372 or saline solution (life table analysis). *Saline-treated guinea pigs without EMG electrode array in which the estimate of the time of delivery was taken as the time of peak uterine activity (see text).

but recovered to previous levels subsequently. Plasma concentrations of estradiol were at or below the sensitivity of the assay.

\section{Discussion}

This study suggests that oxytocin is not involved in the mechanism of the onset and the timing of labor in guinea pigs. Oxytocin receptor blockade delayed the onset of the expulsive phase of labor, which could have been due to a prolonged first stage of labor and/or a delayed onset of labor. As the time of the onset of labor cannot be determined with precision because uterine activity increases progressively (reference 30 and Fig. 3 ), peak uterine activity (maximum uterine activity per hour) was used in this study as a reference point for labor. Any delay in peak uterine activity would have indicated a delay in the onset of labor or a prolonged interval between the onset of labor and the time when peak uterine activity was attained. In several animals treated with oxytocin receptor blockade, peak uterine activity was only marginally greater than the fluctuating baseline uterine activity. Consequently, an additional marker of labor was needed to confirm that peak uterine activity represented

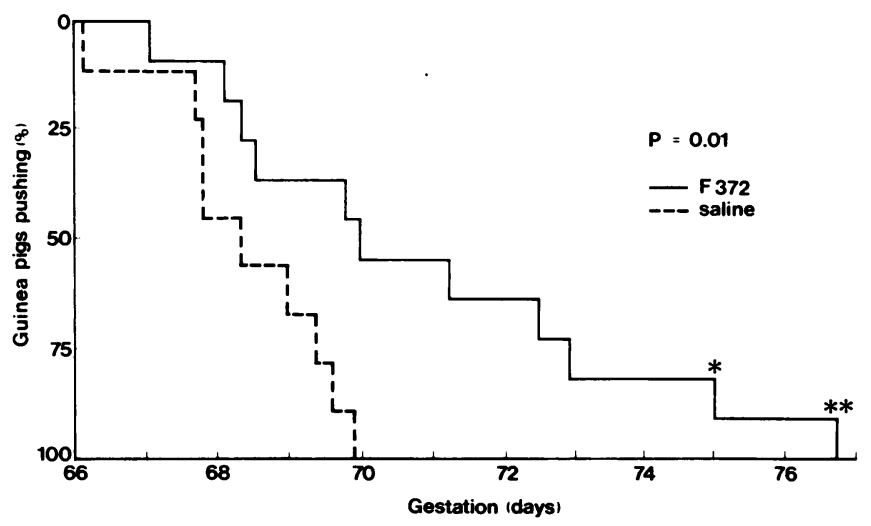

Figure 5. Time of onset of the second stage of labor (expulsive phase) in guinea pigs treated with the oxytocin receptor blocker F372 or saline solution. Right-censored for life table analysis: *pushing during oxytocin infusion; **pushing after stopping F372.

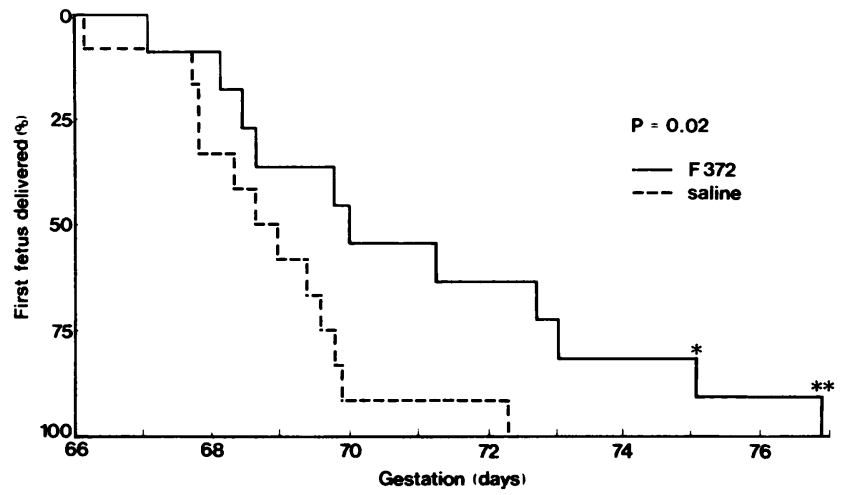

Figure 6. Time of delivery of the first fetus in guinea pigs treated with the oxytocin receptor blocker F372 or saline solution. Right-censored for life table analysis: *delivered during oxytocin infusion; **delivered vaginally after stopping F372.

labor. In all 20 guinea pigs in which uterine EMG activity was recorded, the relative frequency of NEMGA intervals of $<30$ $s$ length decreased with the occurrence of peak uterine activity and the relative frequency of NEMGA intervals lasting 121$600 \mathrm{~s}$ increased. In view of the consistency of these changes and their association in controls with labor, it appears plausible that peak uterine activity in oxytocin receptor-blocked guinea pigs represented labor, irrespective of whether this was accompanied by pushing and delivery of fetuses. The underlying mechanism for the observed changes in the relative frequency of NEMGA intervals is unknown. Uterine activity began to increase $\sim 36 \mathrm{~h}$ before peak activity was achieved in both F372treated guinea pigs and controls (Fig. 3), resembling the time course of uterine activity preceding labor in humans (30). The timely onset in the rise of uterine activity, the timely attainment of peak uterine activity accompanied by a timely change from a prepartum to a postpartum pattern of EMG activity (NEMGA intervals), and the delayed onset of the second stage of labor during oxytocin receptor blockade suggest that oxytocin is necessary for the progress of the first stage of labor but is not involved in the mechanisms of the onset and the timing of labor.

Oxytocin receptor blockade prolonged the duration of the expulsive phase of labor. The likely cause was inadequate uter-

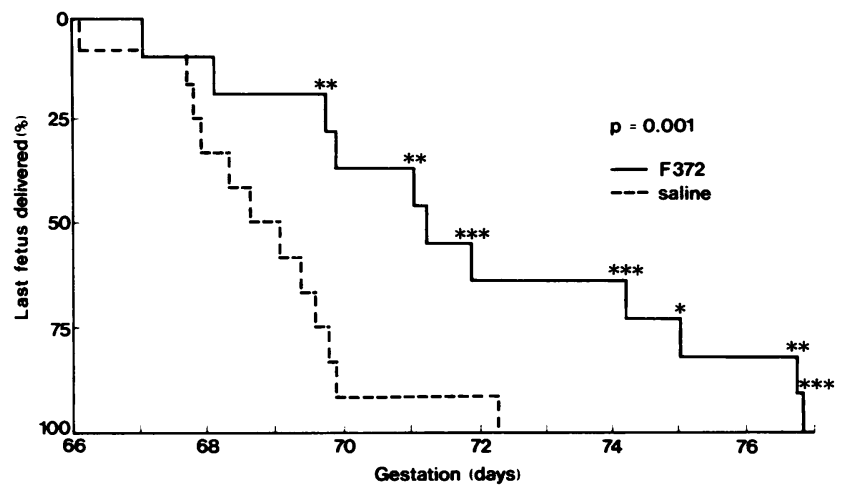

Figure 7. Time of delivery of the last fetus in guinea pigs treated with the oxytocin receptor blocker F372 or saline solution. Right-censored for life table analysis: *delivered during oxytocin infusion; $* *$ delivered vaginally after stopping F372; ***delivered by uterotomy after stopping F372. 


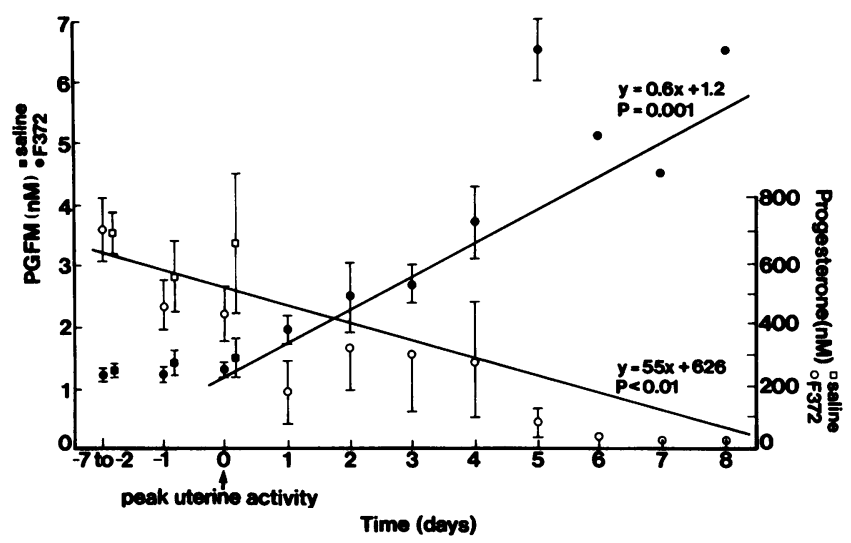

Figure 8. Concentrations in maternal plasma of PGFM and progesterone in guinea pigs treated with the oxytocin receptor blocker F372 or saline solution. Values at Time -7 to -2 are pooled values from 7 to $2 \mathrm{~d}$ before the day of peak uterine activity; regression equation for PGFM concentrations (F372-treated), values from the day of peak uterine activity to $8 \mathrm{~d}$ after peak activity $(n=5)$; equation for progesterone concentrations (F372-treated), from $2 \mathrm{~d}$ before peak activity to $8 \mathrm{~d}$ after peak activity $(n=6)$. Values are mean \pm SEM.

ine action; the mean area of the quasi-integrated EMG during the hour of peak activity was $40 \%$ of controls and the mean frequency of contractions during delivery of the first fetus was $50 \%$ of controls. Whether oxytocin receptor blockade led, in addition, to a lower intrauterine pressure increment for a given EMG activity is unknown; the intrauterine pressure increment is correlated with the area of the EMG envelope in spontaneous and oxytocin stimulated contractions (28) but the relationship has not been established during oxytocin receptor blockade. These observations suggest a prominent role for oxytocin during the expulsive phase of labor.

Oxytocin is required for the normal progress of parturition in guinea pigs; receptor blockade resulted in increased mortality of fetuses and may have caused maternal death if the experiments had not been terminated. Fetal demise was correlated with the length of gestation, which was possibly due to declining placental function as documented in humans (31) and suggested in this study by decreasing progesterone concentrations in maternal plasma after peak uterine activity. These results are at variance with observations in rats in which oxytocin receptor blockade did not delay delivery (27), adding to other differences between the two species; pregnancy is corpus luteumdependent in rats but not in guinea pigs (1), and inhibition of PG synthesis by naproxen sodium in rats prolongs gestation (27) while several PG synthase inhibitors were ineffective in prolonging gestation in guinea pigs (Schellenberg, J. C., unpublished observations ).

The dose rate of oxytocin required to double basal uterine activity in the presence of F372 was 16-32 times greater in the two guinea pigs tested in this study than the dose rate required in the absence of F372 in guinea pigs near term ( $n=$ total of 46 infusions in 10 guinea pigs) (reference 28 and Schellenberg, J. C., manuscript in preparation). The degree of oxytocin receptor blockade achieved in this study is therefore likely to have been adequate for testing the role of oxytocin in parturition of guinea pigs.

The main metabolite of $\mathrm{PGF}_{2 \alpha}$ in guinea pigs, PGFM (32), did not increase consistently preceding and during labor, but increased progressively in oxytocin receptor-blocked guinea pigs which continued to carry fetuses after peak uterine activity had occurred. This is in keeping with an inconsistent but overall significant small rise in PGF preceding and during labor reported in guinea pigs (33) and an increase in plasma concentrations of PGFM during the late stages of labor in humans (2). The progressive increase in the concentrations of PGFM after peak uterine activity offers further support to the proposed interpretation of peak uterine activity representing labor in F372treated animals. Progesterone concentrations in this study are consistent with those reported in the literature regarding their absolute levels and their inconsistent change preceding labor (33-36). The observed plasma concentrations of estradiol in the $\leq 20$ picomolar range were similar to those reported previously $(34,35)$.

In conclusion, the present study demonstrates that oxytocin is requisite for the normal progress of the first and the second stage of labor in guinea pigs. Oxytocin receptor blockade leads to increased fetal mortality associated with inadequate uterine activity which is due, at least in part, to infrequent contractions. Oxytocin has a minor stimulatory effect on the frequency of uterine contractions preceding labor but is not involved in the mechanism of the onset and the timing of labor; this is suggested by the timely occurrence of peak uterine activity during oxytocin receptor blockade accompanied by a timely change from a prepartum to a postpartum pattern of EMG activity following an unaltered progressive increase in baseline uterine activity. Given the fundamental similarities between the endocrinology of pregnancy in guinea pigs and humans (1) oxytocin may play a similar role in human parturition.

\section{Acknowledgments}

Mr. S. Withy is gratefully acknowledged for programming software, Mr. A. Stewart for statistical advice, Mr. K. Townend for assistance with computing, and Mr. W. Kirkby, Mrs. J. Mitchell, Mrs. L. Nisbet and staff of the Surgical Laboratory for technical assistance. F372 was graciously provided by Dr. Per Melin, Ferring AB, Malmö, and the PGFM antibody was a gift from Professor G. D. Thorburn, Department of Physiology, Monash University, Melbourne, Australia.

This study was supported by grant $92 / 62$ from the New Zealand Health Research Council.

\section{References}

1. Liggins, G. C., and G. D. Thorburn. 1994. Initiation of parturition. In Marshall's Physiology of Reproduction. G. E. Lamming, editor. Chapmann and Hall, London. 863-1002.

2. MacDonald, P. C. 1993. Parturition: biomolecular and physiological processes. In Williams Obstetrics. F. G. Cunningham, N. F. Gant, P. C. MacDonald, L. C. Gilstrap, and K. J. Leveno, editors. Prentice-Hall, London. 297-361.

3. Thorburn, G. D., and G. C. Liggins. 1994. Role of the fetal pituitary-adrenal axis and placenta in the initiation of parturition. In Marshall's Physiology of Reproduction. G. E. Lamming, editor. Chapmann and Hall, London. 1003-1036.

4. Challis, J. R. G., and D. M. Olson. 1988. Parturition. In The Physiology of Reproduction. E. Knobil and J. Neill, editors. Raven Press New York. 21772215.

5. Ainsworth, L., M. Daenen, and K. J. Ryan. 1969. Steroid hormone transformations by endocrine organs from pregnant mammals. IV. Biosynthesis and metabolism of estrogens and progesterone by primate placental preparations in vitro. Endocrinology. 84:1421-1429.

6. Word, R. A., K. E. Kamm, and M. L. Casey. 1992. Contractile effects of prostaglandins, oxytocin, and endothelin-1 in human myometrium in vitro: Refractoriness of myometrial tissue of pregnant women to prostaglandins $E_{2}$ and $\mathrm{F}_{2 \alpha}$. J. Clin. Endocrinol. Metab. 75:1027-1032.

7. Fuchs, A. R., R. Romero, D. Keefe, M. Parra, E. Oyarzun, and E. Behnke. 1991. Oxytocin secretion and human parturition: pulse frequency and duration 
increases during spontaneous labor in women. Am. J. Obstet. Gynecol. 165:15151523.

8. Schofield, B. M. 1964. Myometrial activity in the pregnant guinea-pig. $J$. Endocrinol. 30:347-354.

9. Leake, R. D. 1990. Oxytocin in the initiation of labor. In Uterine FunctionMolecular and Cellular Aspects. M. E. Carsten and J. D. Miller, editors. Plenum Press, New York. 361-371.

10. Thornton, S., J. M. Davison, and P. H. Baylis. 1992. Plasma oxytocin during the first and second stages of spontaneous human labour. Acta Endocrinol. 126:425-429.

11. Leake, R. D., R. E. Weitzman, T. H. Glatz, and D. A. Fisher. 1981. Plasma oxytocin concentrations in men, nonpregnant women, and pregnant women before and during spontaneous labour. J. Clin. Endocrinol. Metab. 53:730-733.

12. Burton, A. M., D. V. Illingworth, J. R. G. Challis, and A. S. McNeilly 1974. Placental transfer of oxytocin in the guinea-pig and its release during parturition. J. Endocrinol. 60:499-506.

13. Hirst, J. J., G. J. Haluska, M. J. Cook, D. L. Hess, and M. J. Novy. 1991 Comparison of plasma oxytocin and catecholamine concentrations with uterine activity in pregnant rhesus monkeys. J. Clin. Endocrinol. Metab. 73:804-810.

14. Honnebier, M. B. O. M., J. P. Figueroa, J. P. Rivier, W. Vale, and P. W. Nathanielsz. 1989. Studies on the role of oxytocin in late pregnancy in the pregnant rhesus monkey: plasma concentrations of oxytocin in the maternal circulation throughout the 24-h day and the effect of the synthetic oxytocin antagonist [1$\left.\beta-\mathrm{Mpa}\left(\beta-9 \mathrm{CH}_{2}\right)_{5}\right)_{1},\left(\mathrm{Me}\left(\mathrm{Tyr}^{2}, \mathrm{Orn}^{8}\right]\right.$ oxytocin on spontaneous nocturnal myometrial contractions. J. Dev. Physiol. 12:225-232.

15. Soloff, M. S. 1990. Oxytocin receptors in the uterus. In Uterine FunctionMolecular and Cellular Aspects. M. E. Carsten and J. D. Miller, editors. Plenum Press, New York. 373-392.

16. Fuchs, A. R., F. Fuchs, P. Husslein, and M. S. Soloff. 1984. Oxytocin receptors in the human uterus during pregnancy and parturition. Am. J. Obstet. Gynecol. 150:734-741.

17. Rivera, J., A. Lopez-Bernal, M. Varney, and S. P. Watson. 1990. Inosito 1,4,5-triphosphate and oxytocin binding in human myometrium. Endocrinology. 127:155-162.

18. Alexandrova, M., and M. S. Soloff. 1980. Oxytocin receptors and parturition in the guinea pig. Biol. Reprod. 22:1106-1111.

19. Fuchs, A. R., A. Vangsted, M. Ivanisevic, and K. Demarest. 1989. Oxytocin antagonist (dTVT) and oxytocin receptors in myometrium and decidua. Am. J. Perinatol. 6:205-208.

20. Fuchs, A. R., P. Husslein, and F. Fuchs. 1981. Oxytocin and the initiation of human parturition. II. Stimulation of prostaglandin production in human decidua by oxytocin. Am. J. Obstet. Gynecol. 141:694-697.

21. Wilson, T., G. C. Liggins, and D. J. Whittaker. 1988. Oxytocin stimulates the release of arachidonic acid and prostaglandin $\mathrm{F}_{2 \alpha}$ from human decidual cells Prostaglandins. 35:771-780.

22. Benedetto, M. T., F. De Cicco, F. Rossiello, A. L. Nicosia, G. Lupi, and
S. Dell'Acqua. 1990. Oxytocin receptor in human fetal membranes at term and during labour. J. Steroid Biochem. 35:205-208.

23. Fukai, H., K. Den, H. Sakamoto, H. Kodaira, F. Uchida, and S. Takagi. 1984. Study of oxytocin receptor: II. Oxytocin and prostaglandin $F_{2 \alpha}$ receptors in human myometria and amnion-decidua complex during pregnancy and labor. Endocrinol. Japon. 31:565-570.

24. Chibbar, R., F. D. Miller, and B. F. Mitchell. 1993. Synthesis of oxytocin in amnion, chorion, and decidua may influence the timing of human parturition. J. Clin. Invest. 91:185-192.

25. Akerlund, M., P. Strömberg, A. Hauksson, L. F. Andersen, J. Lyndrup, J. Trojnar, and P. Melin. 1987. Inhibition of uterine contractions of premature labour with an oxytocin analogue. Results from a pilot study. Br. J. Obstet. Gynaecol. 94:1040-1044.

26. Wilson, L., Jr., M. T. Parsons, and G. Flouret. 1991. Inhibition of oxytocininduced uterine contractions by an oxytocin antagonist in the pregnant baboon Am. J. Obstet. Gynecol. 165:456-460.

27. Chan, W. Y., I. Berenzin, E. E. Daniel, K. C. Russell, and V. J. Hruby. 1991. Effects of inactivation of oxytocin receptor and inhibition of prostaglandin synthesis on uterine oxytocin receptor and gap junction formation and labor in the rat. Can. J. Physiol. Pharmacol. 69:1262-1267.

28. Schellenberg, J.-C., P. Lacey, and S. Withy. 1993. Recording and analysis of uterine activity in pregnant guinea pigs. J. Dev. Physiol. 20:1-8.

29. Aurell, C. J., E. Johansson, R. Persson, L. Berden, A. Nilsson, J. Trojnar, M. Abbe, K. Ekholm, C. Hansson, A. Nylen, A. Rosenqvist, B. Johansson, C. Persson, and P. Melin. 1993. Synthesis and pharmacological properties of some carba-6 and carba-1 oxytocin antagonists. In Peptides 1992. C. H. Schneider and A. N. Eberle, editors. ESCOM Science Publishers, Leyden. 697-699.

30. Nageotte, M. P., W. Dorchester, M. Porto, K. A. Keegan, and R. K. Freeman. 1988. Quantitative uterine activity preceding preterm, term, and postterm labor. Am. J. Obstet. Gynecol. 158:1254-1259.

31. Phelan, J. P. 1989. The postdate pregnancy: an overview. Clin. Obstet. Gynecol. 32:221-227.

32. Granström, E. 1971. Metabolism of prostaglandin $F_{2 \alpha}$ in guinea pig lung. Eur. J. Biochem. 20:451-458.

33. Kendall, J. Z. 1977. Studies on the endocrinology of parturition in the guinea pig. Thesis, University of Auckland. 248 pp.

34. Illingworth, D. V., J. R. G. Challis, N. Ackland, A. M. Burton, R. B Heap, and J. S. Perry. 1974. Parturition in the guinea-pig: plasma levels of steroid hormones, steroid-binding proteins, and oxytocin, and the effect of corticosteroids, prostaglandins and adrenocorticotrophin. J. Endocrinol. 63:557-570.

35. Challis, J. R. G., R. B. Heap, and D. V. Illingworth. 1971. Concentrations of oestrogen and progesterone in the plasma of non-pregnant, pregnant and lactating guinea-pigs. J. Endocrinol. 51:333-345.

36. Heap, R. B., and R. Deansly. 1966. Progesterone in systemic blood and placentae of intact and ovariectomized pregnant guinea-pigs. J. Endocrinol. 34:417-423. 